DOCTRINA

\title{
La demanda del pueblo afrochileno por el reconocimiento: La construcción del derecho a la visibilidad estadística
}

\author{
The Afrochilean people's demand for recognition: \\ The construction of the right to statistical visibility
}

\author{
Felipe Guerra Schleef \\ Universidad Austral de Chile \\ Catalina Büchner Ruiz \\ Universidad Austral de Chile
}

\begin{abstract}
RESUMEN Durante las últimas décadas, el pueblo afrochileno ha vivido procesos de «etnificación» y politización de su identidad colectiva, los cuales se han expresado, entre otras cosas, en su demanda por visibilidad estadística. Estos procesos se han repetido en diversos países del continente americano, lo que ha abierto un espacio para el desarrollo y la construcción de repertorios de acción de los movimientos sociales de afrodescendientes, y ha venido acompañada del desarrollo y universalización de los derechos económicos, sociales y culturales. El presente trabajo tiene como objetivo exponer y examinar la demanda del pueblo afrochileno por ser incorporado en los censos de población que organiza el Estado de Chile. Además, se analiza tanto el contenido como los fundamentos de la demanda del pueblo afrochileno a partir del derecho internacional de los derechos humanos, lo que permite la politización de su identidad étnica construida en torno a la categoría de «pueblo tribal».
\end{abstract}

PALABRAS CLAVE Pueblo afrochileno, pueblo tribal, derechos humanos, visibilidad estadística.

ABSTRACT During the last decades, the Afrochilean people have experienced processes of "ethnification" and politization of their collective identity, which have been expressed through their demand for statistical visibility, among others. These processes have occurred in different countries of the American continent, which have provided an opportunity for the development and construction of repertoires of action of the Afro-descendants. This has been accompanied by the development and universalization 
of economic, social, and cultural rights. The objective of this paper is to present and examine the Afrochilean people's demand to be incorporated in the population censuses carried out by the Chilean State. In addition, the content and fundaments of such demand are analyzed drawing from the international law on human rights, which allows for the politization of the Chilean Afro-descendants' ethnic identity articulated around the category of "tribal people".

KEYWORDS Afrochilean people, tribal people, human rights, statistical visibility.

\section{Cuestiones previas: El problema de las cifras}

En las últimas décadas, los contextos sociopolíticos de los países de América Latina han estado marcados por las demandas por un mayor reconocimiento de la diversidad cultural. Dichas reivindicaciones han irrumpido con la reemergencia de movimientos de pueblos indígenas y afrodescendientes que se han posicionado como importantes actores sociales y políticos, logrando situar sus demandas de reconocimiento y autonomía en las agendas nacionales e internacional, al mismo tiempo que han promovido la construcción de una ciudadanía basada en la diferencia y el pluralismo cultural (Antón y Del Popolo, 2009: 17).

La emergencia de la diversidad y la identidad de los pueblos indígenas, afrodescendientes y otros grupos étnicos y colectivos históricamente marginados ha tenido lugar de manera simultánea al desarrollo y universalización de los derechos económicos, sociales y culturales. Así, se ha visibilizado y legitimado la necesidad de que los pueblos indígenas y afrodescendientes accedan de manera equitativa e igualitaria a una ciudadanía moderna (Bello y Rangel, 2000: 43 y ss.). Lo anterior, entre otras cosas, ha llevado a los Estados al diseño e implementación de políticas públicas con pertinencia cultural, que permitan superar las brechas de desigualdad que se manifiestan sistemáticamente entre los grupos antes mencionados y el resto de la población nacional, producto de la discriminación estructural que perdura en los países de la región, y que tiene sus orígenes en el colonialismo europeo y la conformación de los Estados nacionales en el continente Americano (Antón y Del Popolo, 2009: 15).

En este contexto, uno de los problemas fundamentales es el de las cifras y estadísticas. En efecto, tal como ha manifestado la Comisión Interamericana de Derechos Humanos (CIDH), «sin datos confiables, sin indicadores y mediciones periódicas es imposible tomar decisiones políticas destinadas a enfrentar el problema de la discriminación» ( $\mathrm{CIDH}$, 2011: párrafo 38). Además, las cifras comportan un innegable componente político en los procesos de conformación de identidad de los colectivos, al tener la capacidad de generar visibilización y reconocimiento frente a otros, generándose un fenómeno de movilización y autoafirmación positiva tanto del individuo como de los grupos culturales (Antón y Del Popolo, 2009: 20). De esta manera, al 
exigir la inclusión de un enfoque étnico en las fuentes de datos demográficos y sociales de los Estados - como censos de población, encuestas de hogares y registros de salud, entre otros-, los pueblos indígenas y afrodescendientes han impulsado sus demandas por reconocimiento, al mismo tiempo que han promovido la construcción de una ciudadanía basada en la diferencia y el pluralismo cultural. Esto ha llevado a diversos organismos internacionales de protección de derechos y de cooperación a recomendar a los Estados que, como parte de sus obligaciones en materia de derechos humanos, adopten medidas para promover la autoidentificación de sus grupos étnicos en todos los registros públicos y, específicamente, en los censos de población y encuestas de hogares.

Si bien en América Latina se han dado importantes avances en el reconocimiento de los pueblos indígenas en los censos y estadísticas oficiales, en el caso de las poblaciones afrodescendientes - a pesar de su masiva presencia en todos los países del continente-, las preguntas que permiten identificar la pertenencia, ubicación y características de estos grupos han sido incluidas en los mecanismos estadísticos de relevamiento de población solo en tiempos más recientes. Esta contradicción ha sido señalada como el mayor ejemplo de la situación de invisibilización y discriminación que aún padecen los pueblos afrodescendientes en la región (CIDH, 2011: párrafo 24).

Chile no ha estado ajeno a esta tendencia. Aun cuando el país ha dado pasos importantes en la incorporación en los censos y estadísticas oficiales de la variable de pertenencia a pueblos indígenas basada en criterios de autoidentificación, no ha existido el mismo reconocimiento en relación con la población afrochilena. Más grave aún, en los últimos años, Chile se ha transformado en el único país de la región que se resiste a la inclusión de la variable «afrodescendientes» en la pregunta sobre pertenencia étnica en sus censos de población. Lo anterior, pese a las constantes solicitudes por parte de la población afrochilena de la región de Arica y Parinacota y de que organismos internacionales hayan emplazado al Estado a ajustar sus estándares de levantamiento de información estadística a las pautas y recomendaciones internacionales en la materia. ${ }^{1}$ Esto ha hecho que las organizaciones afrodescendientes de Arica

1. La necesidad de contar con información oficial y desagregada, que incorpore la dimensión étnica basada en la autoidentificación, con el objetivo de implementar políticas públicas focalizadas y pertinentes a los miembros de las comunidades afrodescendientes en Chile, ha sido observada y recomendada por el Comité para la Eliminación de la Discriminación Racial en sus observaciones finales sobre los informes periódicos 19 a 21 de Chile (disponible en http://bit.ly/2JRsnho). Asimismo, en dichas observaciones, el Comité lamentó la ausencia de reconocimiento legal por parte del Estado de Chile de la población afrochilena y expresó su preocupación por la falta de información oficial sobre la situación de derechos humanos de las personas afrodescendientes en el país, instando al Estado a cumplir con lo estipulado en su Recomendación General 34 (disponible en http://bit.ly/2xPMtCH) sobre la discriminación racial contra afrodescendientes, y en particular, a que adopte medidas para identificar a los comunidades afrodescendientes que habitan en el territorio nacional. 
deban llevar su reclamo a instancias internacionales, encontrándose actualmente en tramitación una denuncia en contra del Estado de Chile ante la CIDH. ${ }^{2}$

El presente trabajo tiene como objetivo exponer y analizar la demanda del pueblo afrochileno de ser incorporado en los censos de población que organiza el Estado de Chile. Para lo anterior, el artículo se divide en cuatro partes. En primer lugar, se entregan antecedentes de la población afrodescendiente en el territorio que actualmente corresponde a la región de Arica y Parinacota. Éstos permiten precisar el colectivo afrodescendiente específico al que aludimos, quienes han habitado en el norte del país desde tiempos previos a la conformación del Estado de Chile, y cuya identidad cultural y política tiene su origen en los descendientes de la diáspora africana que llegó al continente producto de la trata y comercio de esclavos durante la época colonial. En segundo lugar, se exponen algunos antecedentes respecto de la articulación del movimiento afrodescendiente en el norte de Chile, para luego ofrecer una descripción de la situación actual de la población afrochilena de la región de Arica y Parinacota, a partir de datos recogidos de la primera Encuesta de Caracterización de la Población Afrodescendientes de la Región de Arica y Parinacota (ENCAFRO). En tercer lugar, se analiza el contenido y los fundamentos de la demanda del pueblo afrochileno a partir del derecho internacional de los derechos humanos, lo que permite la politización de su identidad étnica construida en torno a la categoría de "pueblo tribal». Por último, se ofrecen algunas consideraciones finales.

\section{Antecedentes históricos de los afrodescendientes de la región de Arica y Parinacota}

La presencia masiva de población de origen africano en las ciudades limítrofes de Arica y Tacna ${ }^{3}$ data del siglo XVI, al igual que en otros países del continente, previo a la formación de los Estados americanos, y tiene sus raíces históricas en la esclavitud y el colonialismo europeo en el hemisferio occidental. En el caso de Arica y Tacna, el tráfico de esclavos estuvo asociado, fundamentalmente, a la explotación de las minas de plata de Potosí. En 1546, Arica fue habilitado como puerto de salida de los minerales que se explotaban en Potosí, y en 1574, por decreto del virrey Francisco de Toledo, se oficializó su denominación como puerto de Potosí (Artal, 2012).

Durante el periodo colonial, cuando el puerto de Arica se encontraba bajo la administración del virreinato del Perú, la población afrodescendiente era muy numerosa. Artal (2012: 4) señala que durante la primera mitad del siglo XVIII se reportaba que en el valle de Lluta los negros y mestizos de negros alcanzaban a ser el $40 \%$ de la

\footnotetext{
2. Se trata de la petición P-1801-16, Cristián Báez Lazcano y otros con Chile.

3. La distancia aproximada entre Arica y Tacna es de $55 \mathrm{~km}$. Arica se ubica en la actual región de Arica y Parinacota en Chile, mientras que Tacna está emplazada en el departamento de Tacna, Perú.
} 
población. Algunos autores como Salgado (2014) han sostenido que, en dicho valle, los esclavistas Francisco Yáñez, Luis Carrasco y Ambrosio Sánchez mantuvieron un criadero de esclavos, donde mujeres y hombres eran encerrados en establos para procrear y luego vender a sus descendientes también como esclavos. Esta idea ha sido también sostenida por Wormald (1966), quien encontró en los archivos parroquiales muchos casos de niños menores de un año, quienes fueron bautizados durante la misma época. ${ }^{4}$

La masiva presencia afrodescendiente en Arica se mantuvo durante el siglo XIX, cuando dicho territorio formaba parte de la República del Perú. Un censo de población organizado en el año 1846 indica que, en la provincia de Arica, del total censado, el 50\% eran negros. En la ciudad de Arica los negros representaban el 54\% de la población, mientras que en el valle de Azapa la presencia afrodescendiente representaba el $68 \%$. El último censo de población correspondiente al periodo en análisis es de 1871, y registra un fuerte descenso de la población afrodescendiente, representando solo el $17 \%$ del total provincial y el $32 \%$ en la ciudad de Arica (Salgado, 2014: 165166). La población afrodescendiente en la provincia de Arica se asentó en los valles de Azapa, Lluta y Codpa, y esa presencia persiste hasta la actualidad. También hubo asentamientos urbanos en las zonas de La Chimba y Lumbanga, localizadas en la ciudad de Arica, los que desaparecieron a comienzos del siglo XX.

La guerra del Pacífico (1979-1883) implicó la anexión de Arica a Chile, lo cual tuvo graves repercusiones en las comunidades afrodescendientes. La guerra concluyó con la firma del Tratado de Ancón el 20 de octubre de 1883, por medio del cual Perú cedió incondicionalmente la provincia de Tarapacá a Chile y se dispuso que Arica y Tacna quedaran bajo administración chilena por un periodo de diez años, al cabo del cual se definiría la soberanía de este territorio a través de un plebiscito. Sin embargo, el plebiscito fijado inicialmente para el año 1904 fue postergado en múltiples ocasiones y, finalmente, nunca se organizó. Más tarde, en 1929, se suscribió el Tratado de Lima, en el cual se dispuso que Tacna quedaría bajo soberanía peruana y Arica bajo la chilena.

Sin perjuicio de lo anterior, el momento más dramático para los afrodescendientes se vivió en los tiempos previos a la supuesta organización del plebiscito aludido, cuando se amedrentó sistemáticamente a la población que habitaba los territorios que en ese momento se encontraban bajo ocupación chilena. Dicho proceso se caracterizó por la imposición de la cultura chilena y la estigmatización de los íconos peruanos. Este periodo se conoce como «chilenización», y se caracteriza por una fuerte inversión pública en infraestructura, cuarteles y escuelas, y la migración de chilenos criollos provenientes del centro y sur a los territorios del norte del país. Durante esta época, la población peruana residente en Arica y los valles fue perseguida y atemori-

4. Sin embargo, cabe mencionar que se trata de una tesis que, hasta ahora, no ha sido aprobada ni refutada por historiadores investigadores de temáticas afrodescendientes en Arica. 
zada, con el fin de que cambiaran su nacionalidad y adhiriesen a la causa chilena de cara al plebiscito. Además, fueron despreciados y perseguidos, por ser la afrodescendencia un ícono de la peruanidad, obligándoseles a migrar al Perú. En el curso de este proceso, se registraron grandes matanzas y persecuciones, las que se atribuyen a una cofradía llamada «Sociedad de Nativos Chilenos de Arica» y a grupos nacionalistas autodenominados «Ligas Patrióticas» (Salgado, 2014: 73).

A raíz de la chilenización, la población afrodescendiente abandonó masivamente Arica para asentarse principalmente en la orilla norte del río Sama y en los puertos de Callao e Ilo, en Perú. Como consecuencia de este éxodo, perdieron todos sus bienes y abandonaron sus tierras, las que les fueron usurpadas. Los que no migraron vivieron situaciones de extrema violencia (Salgado, 2014: 72 y ss.). La chilenización implicó, además, la ruptura de lazos familiares y la desestructuración de una sociedad afrodescendiente asentada en las zonas urbanas y rurales de Arica por cuatro siglos. De este proceso surgieron las denominadas «familias plebiscitarias», quienes fueron víctimas de este nuevo éxodo, cuyo responsable directo fue el Estado de Chile y que ha generado una diáspora afroariqueña en Perú.

Si bien la constitución y pérdida de la propiedad sobre la tierra excede el marco del presente artículo, estos datos dan cuenta de la presencia histórica de comunidades afrodescendientes en la zona de Arica, así como de su preexistencia a la conformación y presencia del Estado chileno en los territorios del norte. Además, permiten establecer la responsabilidad histórica del Estado de Chile en los procesos de invisibilización, usurpación de tierras y denegación histórica de derechos de los que han sido víctimas las comunidades afrodescendientes en el norte desde los primeros decenios del siglo XX hasta la actualidad.

\section{El pueblo afrochileno en la región de Arica y Parinacota en la actualidad}

A comienzos del siglo XXI, se advierte el surgimiento y articulación de un movimiento afrodescendiente en Chile. Es así como el año 200o, líderes afrodescendientes de Arica participaron de la primera Conferencia Regional Preparatoria de las Américas, que tuvo lugar en Santiago de Chile, y de la Conferencia Ciudadana, antecediendo a la Conferencia Mundial contra el Racismo, la Discriminación Racial, la Xenofobia y las Formas Conexas de Intolerancia, que se llevaría a cabo el año 2001 en Durban, Sudáfrica (Espinosa, 2015: 176). La importancia de la Conferencia Regional mencionada radica en que en ella se acordó el uso del término «afrodescendiente» para hacer referencia a la población mundial descendiente de la diáspora africana, lo cual fue ratificado en la Conferencia Mundial de Durban. Además, dicha instancia dio pie para que el año 2001 se creara la ONG Oro Negro, organización afrodescendiente pionera en Arica, y desde la cual nacieron otras organizaciones que forman parte del movimiento en la actualidad (Espinosa, 2015: 177). 
Desde su surgimiento, las organizaciones que conforman el movimiento afrochileno han desarrollado una agenda política en su relación con el Estado chileno, la cual se ha enfocado en el proceso de reparación histórica y reconocimiento. Dicha agenda se sustenta sobre tres pilares estrechamente relacionados entre sí: la inclusión de la variable afrodescendiente en las preguntas sobre pertenencia étnica de los censos de población y estadísticas oficiales del Estado; el reconocimiento legal y constitucional del pueblo afrochileno; y la aplicación del Convenio 169 de la Organización Internacional del Trabajo (OIT) al pueblo afrochileno, en tanto pueblo tribal, situándolo como sujeto de los derechos contenidos en dicho tratado internacional sobre derechos humanos específicos de los pueblos indígenas y tribales (Milien, 2015: $15 \mathrm{y} \mathrm{ss.).}$

En el contexto de las estrategias desplegadas por el movimiento afrochileno, y mientras se planificaba el censo de población del año 2012, las organizaciones afrochilenas exigieron al Instituto Nacional de Estadísticas (INE) su reconocimiento en dicho censo. Si bien el INE se negó a ese requerimiento, estuvo dispuesto, junto al gobierno regional y a las organizaciones afrodescendientes, a desarrollar un estudio estadístico de caracterización de la población afrodescendiente de Arica con fondos del gobierno regional, frente a la necesidad de levantar información estadística validada para focalizar políticas públicas con pertinencia cultural en la región de Arica y Parinacota. De esa manera, el año 2011 surgió la Encuesta de Caracterización de la Población Afrodescendiente de la Región de Arica y Parinacota (ENCAFRO), cuyo propósito era estimar la cantidad de población que se autoidentificaba como afrodescendiente y alcanzar una caracterización sociodemográfica, socioeconómica y cultural de esa población con presencia histórica en la región. Esto, dado que, aunque en ese entonces ya existían políticas y recursos públicos regionales dirigidos específicamente a personas y organizaciones afrodescendientes, éstos se estaban invirtiendo sin contar con datos e información desagregada respecto de la situación real y las especificidades culturales de este importante grupo de la población regional. ${ }^{5}$

Así, entre los meses de agosto y noviembre de 2013, el INE aplicó por primera vez la ENCAFRO, y sus resultados fueron publicados en febrero del año 2014. ${ }^{6}$ Entre los datos relevantes que arrojó, es posible mencionar que la población afrodescendiente estimada en la provincia de Arica es de 8.415 personas sobre un universo de 179.172 que corresponde a la población total, según la información censal del año 2002. Esta población afrodescendiente está asentada mayoritariamente en zonas urbanas (7.503

5. Instituto Nacional de Estadísticas, Resolución Exenta 4.737, del 28 de diciembre de 2011, que «Aprueba Convenio Marco de Colaboración y Acta de acuerdo para el estudio de la situación de la etnia afrodescendiente suscrito entre el Gobierno Regional de Arica y Parinacota, el Instituto Nacional de Estadísticas, y los ONG que se indican respectivamente». Disponible en http://bit.ly/2YSDiNG.

6. Instituto Nacional de Estadísticas, «Primera Encuesta de Caracterización de la Población Afrodescendiente: Región de Arica y Parinacota», enero de 2014, disponible en http://bit.ly/2XXqtQB. 
personas) y minoritariamente en zonas rurales (912 personas). La población rural se encuentra concentrada en el valle de Azapa. También hay población afrodescendiente en los valles de Lluta y Codpa.

La mayor concentración de la población según tramo etario corresponde a jóvenes ( 15 a 29 años), quienes representan el $27,1 \%$, mientras que los niños (hasta 14 años) representan el 25,3\%. Otros tramos etarios representan, respectivamente: 45 a 59 años, el 15,2\%; 30 a 44 años, el 17,6\%; y 59 años en adelante, el 14,9\%. Respecto de los niveles de escolaridad de la población afrodescendiente, éstos demuestran el grado de exclusión al que se enfrentan: el 40,5\% de la población afrodescendiente ha completado educación secundaria y solo el 22,2\% educación terciaria o superior.

Entre los criterios que definirían la identidad afrodescendiente en el área de estudio se mencionan, según orden de importancia: la apariencia física $(25,3 \%)$; los bailes que practican (19,2\%); los apellidos (16,7\%); las comidas que se preparan en el hogar (13,5\%); participación en carnavales y ceremonias religiosas (11,3\%); el territorio donde viven (5,4\%); uso de medicina tradicional $(3,3 \%)$; y la vestimenta $(2,7 \%)$.

Las actividades comunitarias desarrolladas en la actualidad por la población afrodescendiente en Arica corresponden a bailes que se practican en cofradías o comparsas. Descienden de las denominadas Cofradías de Morenos, propias del periodo colonial, y se siguen practicando en épocas de carnaval y festividades religiosas del obituario católico que los afrodescendientes han hecho suyas. Su principal ceremonia religiosa es la adoración de la Cruz de Mayo, que se celebra entre los meses de mayo y julio. Esta práctica cultural y espiritual es una actividad de tipo familiar, que se desarrolla principalmente por las familias asentadas en el valle de Azapa y sus descendientes. Cada linaje posee una Cruz de Mayo que ha heredado de sus ancestros y que se ubica en el predio familiar sobre un cerro principal, y protege las tierras y garantiza una buena cosecha. Las familias afrodescendientes denominan sus cruces con el nombre de sus ancestros. Para proteger el lugar donde se ubica la Cruz de Mayo, especialmente aquellas cruces localizadas sobre tierras fiscales o no tituladas, han conformado agrupaciones comunitarias destinadas a desarrollar este culto y garantizar la integridad del espacio territorial que corresponde a cada grupo familiar y su respectiva cruz.

Como se aprecia, la ENCAFRO permitió acceder, por primera vez, a información desagregada que permite caracterizar a la población afrodescendiente de Arica, lo cual es fundamental para definir políticas públicas y focalizar recursos con pertinencia cultural y con enfoque de derechos. Sin embargo, por la dimensión territorial (encuesta regional) y la escasez de recursos económicos, dicha encuesta no abarca la especificidad de toda la población y comunidades afrodescendientes chilenas, ubicadas principalmente en la zona norte de Chile. Finalmente, el propio INE, organismo técnico de la Administración del Estado encargado de las estadísticas y censos oficiales, le ha restado valor a los resultados de la ENCAFRO, señalando que ésta «no 
implica atribuir una categoría jurídica u oficializar a la población que se identificó como afrodescendiente», tratándose de una «encuesta puntual» que «no resulta vinculante para la producción futura de estadísticas que realice el INE, ni representa compromiso por parte de esta institución de considerarlo en el cuestionario censal».?

\section{Fundamentos del derecho del pueblo afrochileno a la visibilidad estadística}

Como destacan Antón y Del Popolo (2009: 26), los procesos de politización de las identidades afrodescendientes en el continente y el desarrollo de movimientos sociales de afrodescendientes han estado íntimamente ligados a la cuestión de la visibilidad estadística. Como ya fue señalado, en el caso de Chile -al igual que otros grupos afrodescendientes en América Latina y el Caribe-, las organizaciones afrodescendientes han solicitado el reconocimiento de la variable «afrodescendiente» en la pregunta sobre pertenencia étnica, junto a los pueblos indígenas. Esto da cuenta del carácter étnico de la construcción de la identidad afrodescendiente (Antón y Del Popolo, 2009: 20 y ss.) y configura el marco jurídico de referencia a partir de las obligaciones de los Estados en materia de derechos humanos, lo cual ha dado sustento a sus demandas y ha permitido sentar las bases para exigir la incorporación de criterios de autoidentificación de estas poblaciones en los censos y las encuestas.

A partir de la década de los noventa, pero con mayor énfasis a principios del siglo $\mathrm{XXI}$, los Estados nacionales declarados como multiétnicos o pluriculturales comenzaron a incorporar en sus instrumentos estadísticos la variable de autoidentificación étnica para pueblos y comunidades afrodescendientes. En el caso de las poblaciones afrodescendientes, la discusión giró en torno a cómo utilizar un conjunto de variables en los cuestionarios censales que permitieran abarcar de manera suficiente las identidades de los descendientes de la diáspora africana en las Américas. En este debate, el centro del problema era si la pregunta sobre identificación étnica debía apuntar a características raciales o, en su lugar, a otros elementos definitorios de la condición étnica, como símbolos, criterios culturales, políticos o religiosos, entre otros, de los afrodescendientes. ${ }^{8}$ Como destacan Antón y Del Popolo (2009: 18), dicho debate no era solo de carácter técnico y metodológico, y no se limitaba a los censos:

7. Dirección Nacional del INE, Ordenanza 2.455, del 28 de diciembre de 2015, que da respuesta a la presentación de las «Asociaciones de Afrodescendientes Azapa Territorio Ancestral».

8. Como destacan Bello y Rangel (2000: 5-6): «Mientras "raza" está asociado a distinciones biológicas vinculadas a atribuciones relativas a genotipos y fenotipos, especialmente con relación al color de la piel, "etnicidad" se vincula a factores de orden cultural a la identidad étnica. Aunque en muchas ocasiones ambas categorías son difícilmente separables. Etnicidad es un concepto postracial que está fuertemente influenciado por el constructivismo y el relativismo cultural, donde se concibe que tanto la raza como factores étnicos son construcciones sociales y culturales». 
El fondo del debate apuntaba a dimensiones estratégicas para el proceso de politización de la identidad y la construcción de repertorios de acción de los movimientos sociales de afrodescendientes. Desde tiempo atrás, organizaciones, intelectuales, activistas, redes comunitarias y demás actores afrodescendientes, que actuaban generando discursos sobre estos conceptos, habían construido estrategias de poder y movilización. En el marco de la discusión sobre los conceptos de «raza» y «etnicidad» se tejieron entonces acciones políticas, se hicieron demandas y se concretaron propuestas sociales. Sobre la base de esas nociones se lograron efectos interesantes en distintos países, tanto en la cultura política como en las políticas culturales de los Estados.

Es en este contexto en el que surge el concepto de «afrodescendiente», que, como se señaló, fue acuñado y reconocido por los Estados de la región en el año 2000 en Santiago, cuando las organizaciones sociales se movilizaron en torno a la Conferencia Regional de las Américas, instancia preparatoria de la Tercera Cumbre Mundial contra el Racismo, la Discriminación Racial, la Xenofobia y las Formas Conexas de Intolerancia, que se organizaría al año siguiente en Durban. El consenso respecto de este nuevo concepto simbolizó el abandono del tradicional término «negro» y su significación racial, para, en su lugar, abordar un modelo más complejo de «identidad étnica», lo cual supuso una ruptura epistemológica de gran significación estratégica y aludió a una evolución conceptual de la identidad cultural y política de los descendientes de la diáspora africana (Antón y Del Popolo, 2009: 20).

Fue precisamente a partir del proceso iniciado en la Conferencia en Durban, en 2001, que las exigencias de reconocimiento estadístico cobraron mayor fuerza, quedando instalada la necesidad de contar con datos oficiales sobre los afrodescendientes, a fin de evaluar y formular políticas de reconocimiento y reparación enfocadas en dicha población. Lo anterior, además, movilizó a diversos organismos internacionales de protección de derechos humanos y de control de tratados, quienes comenzaron a recomendar a los Estados la adopción de medidas para promover la autoidentificación y transversalización de la variable «afrodescendiente» en todos los registros públicos y estadísticas oficiales, cuidando que esa información — sumamente valiosa a los fines estadísticos y de diseño de políticas públicas- no sea utilizada para estigmatizar y revictimizar a la población afrodescendiente.

Así, el año 2011, el Comité para la Eliminación de la Discriminación Racial (CEDR o CERD, por sus siglas en inglés), órgano de control de la Convención Internacional sobre la Eliminación de todas las Formas de Discriminación Racial, adoptó su Recomendación General 34 sobre la Discriminación Racial contra Afrodescendientes, en la que se señala, entre otras cosas, que las personas afrodescendientes

tienen derecho a ejercer, sin discriminación alguna, individual o colectivamente con otros miembros del grupo, según proceda, los siguientes derechos concretos: 
a) el derecho a la propiedad y el derecho al uso, la conservación y la protección de tierras que hayan ocupado tradicionalmente y de recursos naturales, en caso de que sus modos de vida y su cultura estén vinculados a la utilización de esas tierras y recursos;

b) el derecho a su identidad cultural y a mantener, salvaguardar y promover su modo de vida y sus formas de organización, cultura, idiomas y expresiones religiosas;

c) el derecho a la protección de sus conocimientos tradicionales y su patrimonio cultural y artístico;

d) El derecho a que se les consulte previamente cuando se tomen decisiones que puedan afectar a sus derechos, de conformidad con las normas internacionales.

Asimismo, el CEDR establece la obligación de los Estados partes de tomar medidas para identificar a las comunidades afrodescendientes que habitan en sus territorios,

mediante la compilación de datos desglosados de la población, teniendo presentes las Recomendaciones generales del Comité, en particular la núm. 4 (1973) sobre la composición demográfica de la población (artículo 9), la núm. 8 (1990) sobre la manera en que se define la condición de miembro de un determinado grupo o grupos raciales o étnicos (artículo 1, párrafos 1 y 4), y la núm. 24 (1999) relativa a la presentación de informes sobre las personas pertenecientes a diferentes razas, grupos nacionales/étnicos o poblaciones indígenas (artículo 1).

En el sistema regional de protección de derechos humanos, la CIDH ha recomendado a los Estados americanos «adoptar los mecanismos necesarios para promover la autoidentificación de su población afrodescendiente, en especial, mediante la inclusión de la variable "afrodescendencia" en todos los registros públicos y específicamente en los censos de población y encuestas de hogares» (CIDH, 2011). Además, existe un marco de directrices desarrollado al alero del derecho internacional de los derechos humanos, que enfatiza que la elaboración de estadísticas públicas por los Estados debe seguir una lógica pluralista, inclusiva y de ampliación de derechos para todos los sectores de la población, de modo tal que la generación de información sobre población afrodescendiente, población indígena, personas con capacidades diferentes, personas lesbianas, gays, bisexuales y transexuales, y grupos diferenciados de la sociedad, constituya un insumo básico para la elaboración de políticas públicas. Entre estas directrices se encuentran: la Declaración y Programa de Acción de Durban, aprobadas en la Conferencia Mundial contra el Racismo, la Discriminación Racial, la Xenofobia y las Formas Conexas de Intolerancia de 2001; la Resolución 67/155 de la Asamblea General; y el Consenso de Montevideo sobre Población y Desarrollo, fruto de la primera reunión de la Conferencia Regional sobre Población y Desarrollo de América Latina y el Caribe, celebrada en Montevideo del 12 al 15 de agosto de 2013, entre otras. Todas estas directrices cumplen un papel fundamental para asegurar el 
correcto y legítimo desempeño de la potestad que recae en el INE, organismo al cual, conforme a su ley orgánica, le corresponde «levantar los censos oficiales, en conformidad a las recomendaciones internacionales» (Ley 17.374, artículo 2 letra c).

En el caso de la población afrochilena de la región de Arica y Parinacota, al igual que en diversos casos en otros países del continente, ha configurado su identidad colectiva en torno a la categoría de «pueblo tribal», que encuentra reconocimiento en el derecho internacional de los derechos humanos. En efecto, en la mayoría de los países del continente, algunos afrodescendientes se mantienen como colectivos étnica y culturalmente diferenciados, que comparten una identidad, un origen, una historia y una tradición común, como es el caso del pueblo maroon en Surinam, los quilombos en Brasil o las comunidades afrodescendientes en Colombia y Ecuador. En todos estos casos, se trata de sociedades dinámicas, no estáticas, que han atravesado procesos de cambio a través de los años y que mantienen en todo o en parte instituciones sociales, culturales o económicas propias.

Así, el pueblo afrochileno al que hemos hecho referencia, al apelar a su condición de pueblo tribal, ha reivindicado titularidad sobre los derechos colectivos que el derecho internacional de los derechos humanos le reconoce tanto a los pueblos indígenas como a los tribales. El Convenio 169 de la OIT de 1989, al determinar su ámbito de aplicación, define en su artículo 1 a los pueblos indígenas y tribales. Para dicho tratado internacional sobre derechos humanos, los pueblos tribales en países independientes son aquellos grupos «cuyas condiciones sociales, culturales y económicas les [distinguen] de otros sectores de la colectividad nacional, y que [están] regidos total o parcialmente por sus propias costumbres o tradiciones o por una legislación especial» (artículo 1.1 a). A su vez, los pueblos indígenas corresponden a aquellos colectivos

considerados indígenas por el hecho de descender de poblaciones que habitaban en el país o en una región geográfica a la que pertenece el país en la época de la conquista o la colonización o del establecimiento de las actuales fronteras estatales y que, cualquiera que sea su situación jurídica, conservan todas sus propias instituciones sociales, económicas, culturales y políticas o parte de ellas (artículo 1.1 b).

Sin perjuicio de lo anterior, con el objetivo de evitar arbitrariedades al momento de su aplicación, el Convenio 169 especifica: «La conciencia de su identidad indígena o tribal deberá considerarse un criterio fundamental para determinar los grupos a los que se aplican las disposiciones del presente Convenio» (artículo 1.2). Como se aprecia, el énfasis del Convenio 169 de la OIT al momento de determinar su ámbito de aplicación está puesto en la autoidentificación, principio inspirado en la libre determinación y, por tanto, en la facultad soberana de un pueblo de definir su estatus jurídico y membrecía.

Como es posible apreciar, los elementos para la identificación de un pueblo indígena o tribal en el derecho internacional de los derechos humanos son tanto objeti- 
vos como subjetivos. Para el caso de los pueblos indígenas, los elementos objetivos incluyen: i) la continuidad histórica con aquellos grupos anteriores a la conquista o colonización, que determina su preexistencia a los Estados; ii) la conexión territorial, en el sentido de que sus antepasados habitaban el país o la región; y iii) la existencia, en todo o en parte, de instituciones sociales, económicas, culturales y políticas distintivas y específicas. Por su parte, los elementos objetivos de los pueblos tribales incluyen: i) una cultura, organización social, condiciones económicas y forma de vida distintas a las de otros segmentos de la población nacional - por ejemplo, en sus formas de vida, sustento, lengua, etcétera-; y ii) tradiciones y costumbres propias, o un reconocimiento jurídico especial. Finalmente, el elemento subjetivo, requerido tanto para el caso de los pueblos indígenas como tribales, corresponde a la autoidentificación colectiva e individual en tanto tal.

Los organismos del sistema interamericano de protección de derechos humanos han recurrido al concepto de pueblo tribal del Convenio 169 de la OIT para referirse a los grupos afrodescendientes de la región y brindarle protección especial a sus formas de vida y culturas, por cuanto, aunque no son pueblos que puedan ser considerados como indígenas u originarios de las regiones que habitan, al igual que los pueblos indígenas, comparten condiciones que los distinguen de otros sectores de la colectividad nacional. Tanto la Corte Interamericana de Derechos Humanos como la CIDH han tomado y desarrollado los elementos para la identificación de los pueblos tribales para resolver casos en que se alegaban vulneraciones graves de los derechos humanos de esos pueblos. En este contexto, la Corte IDH ha debido ponderar en varias oportunidades si un determinado grupo afrodescendiente reúne las condiciones para ser considerado como pueblo tribal y si, en consecuencia, es titular de los derechos que confiere el Convenio 169 de la OIT. Los más emblemáticos son: Aloeboetoe con Surinam de 1993, Maiwana con Surinam de 2005, y Saramaka con Surinam de 2007.

En la sentencia pronunciada en el caso Saramaka con Surinam, la Corte IDH se vio en la necesidad de valorar si los saramaka podían ser considerados como una comunidad tribal sujeta a la protección que el derecho internacional de los derechos humanos reserva a los pueblos indígenas y tribales. En dicha sentencia, la Corte definió «pueblo tribal» como

un pueblo que no es indígena a la región pero que comparte características similares con los pueblos indígenas, como tener tradiciones sociales, culturales y económicas diferentes de otras secciones de la comunidad nacional, identificarse con sus territorios ancestrales y estar regulados, al menos en forma parcial, por sus propias normas, costumbres o tradiciones (párrafo 79).

De esta manera, al asignar la condición de tribal al pueblo saramaka, la Corte IDH valoró su identificación con sus tierras ancestrales, la preservación de un sistema normativo, y las costumbres y tradiciones propias diferentes al resto de la sociedad 
nacional. La Corte identificó al pueblo saramaka como perteneciente al grupo maroon de Surinam y reconoció que sus ancestros fueron esclavos africanos llevados a la fuerza a ese país durante la colonización europea en el siglo XVII y que, posteriormente, dichos esclavos escaparon a las regiones del interior, donde establecieron comunidades autónomas. Además, de acuerdo a la evidencia proporcionada en el proceso, la sentencia reconoció que este grupo estaba reunido en 63 comunidades distintas, distribuidas en las zonas norte y oeste de Surinam (párrafo 79).

A partir de lo anterior, la Corte concluyó que el pueblo saramaka debía ser considerado un pueblo tribal, toda vez que poseía una estructura social sustancialmente distinta a la de otros sectores de la sociedad. En efecto, la Corte IDH constató que ese pueblo estaba organizado en doce clanes de tipo matriarcal, en los que la pertenencia étnica era definida por linaje materno y mantenía sus propias normas tradicionales y costumbres. Cada clan (lö) reconocía la autoridad política de varios líderes locales, incluyendo a los que ellos llaman capitanes y capitanes jefes, así como un gaa’man, que es el oficial de más alto rango dentro de la comunidad (párrafo 81).

Además, la Corte constató que el pueblo saramaka preserva una relación particular con la tierra, que garantiza su subsistencia y su identidad cultural como pueblo diferenciado. En síntesis, la sentencia resolvió que la presencia de los elementos objetivos mencionados demostraba la condición de pueblo tribal del pueblo saramaka, pues lo caracterizaba como un grupo distinto a otros sectores de la sociedad, tanto en lo cultural como en lo económico y social (párrafos 82-84).

Otro precedente importante respecto a los criterios para identificar la condición de pueblo, consta en la sentencia del 24 de agosto de 2010, en el caso de la Comunidad indígena xákmok kásek con Paraguay. Si bien se trata del caso de un pueblo indígena, una de las cuestiones controvertidas fue la identidad étnica de la comunidad, debido a su composición multiétnica. Esto es una circunstancia que ha sido transversal para el caso de los pueblos tribales de la región. La comunidad indígena xákmok kásek se identificó indistintamente como perteneciente al pueblo enxet, como enxet-lengua y como sanapaná, y sus líderes estaban registrados como líderes de la «comunidad zalazar», lo que implicaba una imprecisión respecto de su etnicidad (párrafos 33-34). La Corte IDH resaltó la conformación multiétnica de la comunidad xákmok kásek, lo que hace parte de su identidad como pueblo diferenciado, y señaló que la determinación de su propia identidad étnica «es un hecho histórico social que hace parte de su autonomía». Como se observa, la Corte IDH puso énfasis en el factor diferenciador de la identidad y la autoidentificación, que, como se señaló, es un criterio fundamental al momento de determinar la condición de indígena o tribal de un pueblo.

En una sentencia reciente, en el caso Comunidad garífuna Triunfo de La Cruzy sus miembros con Honduras de 2015, la Corte IDH reafirmó lo señalado hasta aquí. En su sentencia de fondo, la Corte apreció el origen del pueblo garífuna, señalando que su presencia en el territorio data del siglo XVIII, y surge de la unión de africanos 
provenientes de barcos españoles que naufragaron en la isla San Vicente en 1635 y los amerindios que habitaban la zona desde antes de la colonización, los pueblos indígenas de arawak y kalinagu. De la unión de estos pueblos emergieron los karaphunas, quienes una vez que Reino Unido tomó el control de la isla San Vicente en 1797, fueron deportados a la isla Roatán y de ahí emigraron a tierra firme a los territorios que hoy corresponden a Honduras, asentándose a lo largo de la costa norte hondureña y hacia la costa del Caribe de Guatemala, Nicaragua y Belice. Actualmente, el pueblo garífuna está conformado por aproximadamente 40 comunidades que se extienden a lo largo del litoral atlántico o zona costera del Caribe, abarcando los departamentos de Cortés, Atlántida, Colón y Gracias a Dios. Asimismo, un número creciente de garífunas vive en ciudades como La Ceiba, Tela, Cortés, Trujillo, San Pedro Sula y Tegucigalpa. De esta manera, para la Corte IDH «el pueblo garífuna constituye una cultura y un grupo étnico diferenciado, proveniente de un sincretismo entre indígenas y africanos, quienes han hecho valer sus derechos en Honduras como pueblo indígena» (párrafo 48). Además, la Corte IDH agrega:

Los garífuna se identifican como un pueblo indígena heredero de los caribes insulares, con algunas manifestaciones culturales de origen africano siendo la autoidentificación un criterio subjetivo, y uno de los criterios principales y determinantes recogidos en el artículo 1.2 del Convenio 169 de la OIT, a fin de ser considerado como pueblo indígena o tribal (párrafo 48).

Finalmente, cabe mencionar que la CIDH (2009) ha hecho suya la definición acuñada por la Corte IDH en el caso Saramaka con Surinam, consignando que concuerda con lo establecido en el artículo 1.1 letra a) del Convenio 169 de la OIT. Asimismo, ha enfatizado que, al igual que ocurre con el caso de los pueblos indígenas, la determinación de un grupo como pueblo tribal depende de una combinación de factores objetivos y subjetivos. Además, la CIDH explicita la relevancia de la historia para la identificación de los pueblos indígenas y tribales, que se expresa en la continuidad histórica de su presencia en un determinado territorio. Ello no implica que estas sociedades sean estáticas y permanezcan idénticas a sus antecesores. Lo que se pondera es que mantengan, ya sea en su totalidad o en parte, el legado cultural de sus ancestros y una trayectoria social común en torno a la cual se construye la relación con su territorio, relación que permite su subsistencia física y cultural, y a la cual el derecho internacional ha otorgado un nivel privilegiado de protección.

\section{Consideraciones finales}

Como ha sido ampliamente destacado, los procesos de politización de las identidades afrodescendientes en América han estado íntimamente ligados a la cuestión de la visibilidad estadística, lo que ha abierto un espacio para el desarrollo y la construcción 
de los repertorios de acción de los movimientos sociales de afrodescendientes, y han venido acompañados del desarrollo y universalización de los derechos económicos, sociales y culturales.

En el caso de Chile, y a pesar de los procesos de movilización de las organizaciones afrodescendientes de Arica en orden a obtener un reconocimiento en los instrumentos estadísticos oficiales del Estado de Chile, en los últimos años este país se ha transformado en el único del continente que aún se resiste a incluir la variable «afrodescendiente» en la pregunta sobre pertenencia étnica de sus censos de población, con las consiguientes vulneraciones y denegaciones de derechos que dicha situación implica. Esto, a pesar de haber sido demandado por la población afrochilena de la región de Arica y Parinacota y de tratarse de estándares que se derivan de obligaciones del Estado de Chile en materia de derechos humanos y recomendaciones internacionales en relación al levantamiento de información estadística. Lo anterior ha hecho que las organizaciones afrodescendientes de Arica deban llevar su reclamo a instancias internacionales, encontrándose actualmente en tramitación una denuncia en contra del Estado de Chile ante la CIDH. ${ }^{9}$

La legitimidad y sustento jurídico de la demanda de la población afrochilena de la región de Arica y Parinacota por visibilidad estadística encuentra su fundamento en el derecho internacional de los derechos humanos, que permite reconocer a este grupo étnico como un pueblo tribal, titular de derechos especiales. A nivel internacional, se ha desarrollado una serie de elementos que permiten identificar a dichos pueblos como tales, entre los que cuentan su relación especial y colectiva con el territorio que habitan, la presencia de formas de organización propias, maneras de sustento, lenguas, entre otros, que dan cuenta del ejercicio habitual de su autodeterminación. Junto con ello, se ha establecido un elemento subjetivo, relativo a la consciencia de la respectiva comunidad o pueblo sobre su identidad diferenciada, esto es, una consciencia de identidad grupal que hace que sus integrantes se asuman como miembros de una colectividad. Los órganos del sistema interamericano han afirmado que, en

9. Nota del editor: Después de muchos años de tramitación, el 16 de abril de 2019, se publica en el Diario Oficial la Ley 21.151, que otorga reconocimiento legal al pueblo tribal afrodescendiente chileno. Esta Ley indica en su artículo 1 que otorga el reconocimiento legal al pueblo tribal afrodescendiente chileno, y a su identidad cultural, idioma, tradición histórica, cultura, instituciones y cosmovisión. El artículo 3 reconoce los saberes, conocimientos tradicionales, medicina tradicional, idiomas, rituales, símbolos y vestimentas del pueblo tribal afrodescendiente chileno como patrimonio cultural inmaterial del país. En cuanto a los censos, el artículo 6 indica que el Estado procurará incluir al pueblo tribal afrodescendiente chileno. En su artículo 4, la Ley establece que el sistema nacional de educación de Chile procurará contemplar una unidad programática que posibilite a los educandos el adecuado conocimiento de la historia, lenguaje y cultura de los afrodescendientes, y promover sus expresiones artísticas y culturales desde el nivel preescolar, básico, medio y universitario; en tanto, el artículo 5 reconoce a los afrodescendientes chilenos el derecho a la consulta en términos del Convenio 169 de la OIT. 
tanto una comunidad afrodescendiente u otro grupo étnico reúna ambos elementos, puede ser considerada un pueblo tribal en los términos del Convenio 169, a efectos de su protección bajo el derecho internacional, más allá de la denominación que reciban en el ámbito interno o de que se encuentre formalmente reconocida su existencia por parte de los Estados. De esta forma, los pueblos tribales y sus miembros tienen los mismos derechos que los pueblos indígenas.

En el caso de los afrochilenos de la región de Arica y Parinacota, corresponden a un colectivo conformado por descendientes de la diáspora africana en el continente, cuya presencia histórica en los territorios del norte y preexistencia al Estado de Chile es incuestionable. Además, el pueblo afrochileno es un colectivo que mantiene un sistema de vida y costumbres, además de un proyecto civilizatorio que lo diferencia del resto de la población nacional, y que se autoidentifica como tal. De esta manera, el colectivo que hemos considerado como afrochilenos corresponde a un grupo que construye su identidad en torno a la categoría de pueblo tribal, como titulares de los derechos étnicos, culturales, territoriales y políticos que el derecho internacional de los derechos humanos reconoce a los pueblos indígenas y tribales.

\section{Referencias}

Antón, Jhon y Fabiana del Popolo (2009). «Visibilidad estadística de la población afrodescendiente de América Latina: Aspectos conceptuales y metodológicos». En Jhon Antón, Álvaro Bello, Fabiana del Popolo, Marcelo Paixão y Marta Rangel, Afrodescendientes en América Latina y el Caribe: Del reconocimiento estadístico a la realización de derechos (pp. 13-35). Serie Población y Desarrollo 87. Santiago: Cepal. Disponible en http://bit.ly/2XU8aMj.

Artal, Nathalie (2012). «Á(f)rica: Relatos y memorias afrodescendientes en Arica tras la chilenización y el conflicto entre Perú y Chile (1883-1929)». Aletheia, 2 (4): 1-16. Disponible en http://bit.ly/2XKP4wZ.

BeLlo, Álvaro y Marta Rangel (2000). «Etnicidad, "raza” y equidad en América Latinay el Caribe». Informe Cepal LC/R.1967/Rev.1. Disponible en http://bit. $1 y / 2 Y_{2} U L W v$.

CIDH, Comisión Interamericana de Derechos Humanos (2009). «Derechos de los pueblos indígenas y tribales sobre sus tierras ancestrales y recursos naturales: Normas y jurisprudencia del sistema interamericano de derechos humanos». Informe OEA/Ser.L/V/II. Doc. 56/o9. Disponible en http://bit.ly/2ShPrZO.

-. (2011). «La situación de las personas afrodescendientes en las Américas». Informe OEA/Ser.L/V/II. Doc. 62. Disponible en http://bit.ly/32wO26E.

EsPINOSA, María Paz (2015). «Afrochilenos en Arica: Identidad, organización y territorio». Antropologías del Sur, 3: 175-190. 
Milien, Sandy (2015). «Afrochilenos en rumbo al reconocimiento como pueblo tribal: Una investigación sobre los factores históricos y culturales de los Afrodescendientes en Arica». Independent Study Project (ISP) Collection. Disponible en http://bit.ly/2XXoNXo.

Salgado, Marta (2014). Afrochilenos: Una historia oculta. 2. ${ }^{a}$ ed. Arica: Krom.

Wormald, Alfredo (1966). «El mestizo en el departamento de Arica». Anales de la Universidad del Norte, 5: 183-318.

\section{Sobre los autores}

Felipe Andrés Guerra Schleef es licenciado en Ciencias Jurídicas y Sociales y Magíster en Derecho (mención Derecho Público) de la Universidad Austral de Chile. Actualmente es doctorando del Doctorado en Derecho, mención Constitucionalismo y Derecho, Universidad Austral de Chile, e investigador de la ONG Observatorio Ciudadano. Su correo electrónico es felipe.guerra.schleef@gmail.com.

Catalina Soledad Büchner Ruiz es licenciada en Educación y Magíster en Comunicación de la Universidad Austral de Chile. Actualmente es investigadora de la ONG Observatorio Ciudadano y estudiante de Derecho en la Universidad San Sebastián, Chile. Su correo electrónico es catabuchner@gmail.com. 